\title{
The analysis of qualitative research data in family planning and reproductive health care
}

\author{
Karen Forrest Keenan, Edwin van Teijlingen, Emma Pitchforth
}

\section{Introduction}

This is the third in a series of four papers on the use of qualitative methods in family planning and reproductive health care research. The first paper outlined the three main methods used in qualitative studies ${ }^{1}$ and the second explored how we can assess the 'quality' of qualitative research ${ }^{2}$ This paper addresses issues related to the analysis of qualitative data. It begins by discussing the nature of qualitative data and its management, followed by an outline of the main theoretical assumption pertaining to its analysis, that of 'coding up' (versus 'coding down'). Next we describe some of the major approaches to qualitative data analysis and discuss why you may choose one approach over another. The paper ends by highlighting some general issues in qualitative data analysis.

What is qualitative data and how do you manage it? Qualitative data may include audio tapes, field notes, still or moving images, transcripts of interviews/focus groups or textual material such as published papers or the minutes of meetings. ${ }^{3}$ For example, during data collection on women's experiences of maternity services in Bangladesh, one of the authors (E.P.) gathered raw materials which included field notes, audio tapes and still images. The quantity of qualitative data from even a small study can be overwhelming and an efficient storage and data management and retrieval system is essential. ${ }^{4}$ Several authors provide advice, together with examples, about what to store and how to retrieve and organise it for analysis. ${ }^{3-6}$

\section{Coding and categorising the data}

Coding is the first stage in most qualitative analysis. This allows a set of index categories to be systematically and consistently applied to the whole data set. Different types of code will reflect different readings of the data and these may be literal, interpretive or reflexive. ${ }^{6} \mathrm{~A}$ literal reading of a transcript will take account of things like pauses, interruptions and agreements or disagreements in a conversation. It might also include descriptive data, such as whether a respondent has children or not, marital status, and so on. A code may also be interpretive and will depend

J Fam Plann Reprod Health Care 2005; 31(1): 40-43

(Accepted 31 October 2004)

Departments of Public Health and Medical Genetics, Medical School, University of Aberdeen, Aberdeen, UK Karen Forrest Keenan, MA, MLitt, Research Fellow

Department of Public Health, Medical School, University of Aberdeen, Aberdeen, UK

Edwin van Teijlingen, MEd, PhD, Medical Sociologist/Reader in Public Health

Dugald Baird Centre for Research on Women's Health, University of Aberdeen, Aberdeen and Department of Health Sciences, University of Leicester, Leicester, UK

Emma Pitchforth, BSc, PhD, Research Fellow/Lecturer in Social Science and Health

Correspondence to: Karen Forrest Keenan, Department of Public Health, Medical School, Polwarth Building, University of Aberdeen, Foresterhill, Aberdeen AB25 2ZD, UK.

Tel: +44 (0) 1224 551250. Fax: +44 (0) 1224550529

E-mail: k.forrest@abdn.ac.uk upon what the researcher thinks the respondent is saying or what underlying processes may be inferred. Lastly, codes may be reflexive in that they reflect upon how the researcher played a role in the interview or make suggestions about what they thought was actually going on. In recent years an increasing amount of computer software for qualitative data analysis and management has become available and this may facilitate coding. 4,7

\section{Data analysis: coding up and coding down}

Presenting data analysis as a clearly identifiable process is problematic in that it is inextricably linked with all stages of the research process. ${ }^{8}$ O'Reilly argues that analysis is the phase linking 'writing down' (collecting information and taking notes) to 'writing up' (preparing what you have discovered in a way that can be presented to others). Qualitative analysis, she argues, is "making some sense of it all". 9 Miles and Huberman similarly describe three concurrent stages: data reduction, data display and conclusion drawing/verification. ${ }^{4}$ They also highlight that any process of analysis begins at the very outset of a study from the derivation of research questions, to decisions about focus group schedules and sampling - because this leads to choices about the gathering of certain data and the exclusion of others. Decisions about whether to 'code up' or 'code down' may dramatically change the nature of one's dataset.

\section{Coding down}

Coding down involves coding (i.e. indexing) the dataset using predefined categories, generally from a coding handbook. Hence categories for coding are brought to the data rather than developed from it. ${ }^{10}$ This approach is often used in media studies, for example, Kingori et al. ${ }^{11}$ conducted an analysis of national and regional newspaper coverage of teenage pregnancy based on this approach.

\section{Coding up}

In contrast, coding up does not involve using predefined categories to index the data. Categories (or themes or codes) are developed from the dataset. Coding up is often used when a qualitative approach is chosen to study a phenomenon that has not been previously explored in much depth, for example, the barriers and facilitators in family communication about genetic risk. ${ }^{12}$

The importance of qualitative analysis in refining the subject of research means that the research process is often likened to a funnel because it is through the course of doing fieldwork that the study becomes progressively focused. ${ }^{13}$ Thus, Silverman ${ }^{13}$ cites Hammersley and Atkinson ${ }^{14}$ who describe qualitative research as having: "a characteristic 'funnel' structure, being progressively focused over its course. Progressive focusing has two analytically distinct components. First, over time the research problem is developed or transformed, and eventually its scope is clarified and delimited and its internal structure explored. In this sense, it is frequently only over the course of the research that one discovers what the research is really 'about', and it is not uncommon for it to turn out to be about something quite remote from the initially foreshadowed problems."

Qualitative analysis is, therefore, an ongoing iterative process whereby the researcher is constantly moving between collection and interpretation. 


\section{Approaches to qualitative analysis}

There are many approaches to qualitative analysis all of which have their own strengths and weaknesses. The method one chooses will depend on the purpose of the study, available resources and one's theoretical perspective. Some of the main approaches to visual and non-visual qualitative analysis are outlined below.

\section{Thematic analysis}

A thematic analysis may be undertaken as the initial phase of data analysis, or when a study has limited resources, or as an introduction to analysing qualitative data. The researcher should identify themes from reading and rereading the transcripts, noting any similarities and differences between and within participants' accounts. ${ }^{6}$ Qualitative computer packages (e.g. Nudist ${ }^{\mathrm{TM}}$, Ethnograph $^{\mathrm{TM}}$, Atlas $^{\mathrm{TM}}$ ) can assist in this task of first-level analysis. ${ }^{15}$ Responses can be further categorised (refined) within each main theme after reading the transcripts again in the light of the first thematic analysis to produce the final findings. Box 1 outlines the steps to take when following such an approach.

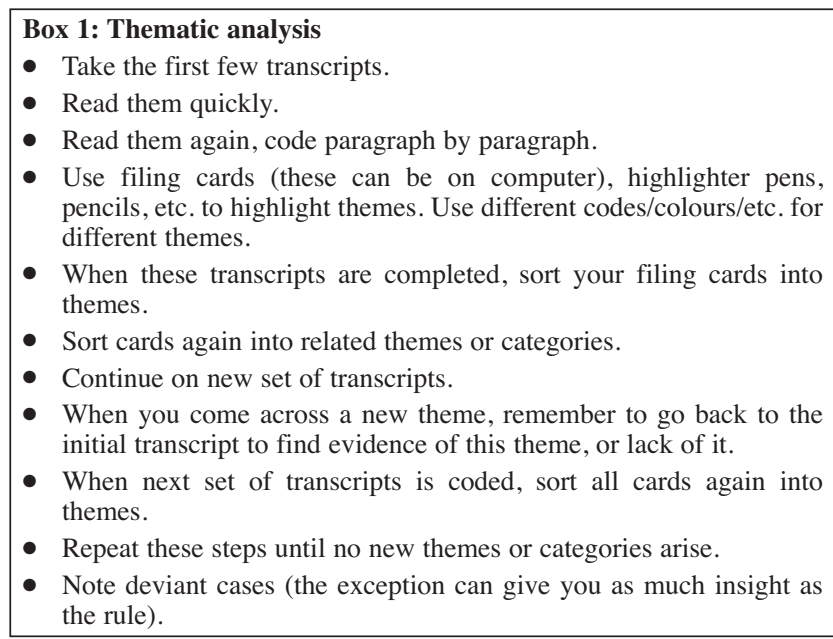

\section{Grounded theory approach}

In contrast to coding down, the emphasis in a grounded theory approach is allowing categories to emerge from the data; this approach is particularly useful if the research problem has not been previously explored or even defined. The researcher conducts a constant comparison of the data and the emergent themes until no more new insights can be obtained. ${ }^{16}$ Starting from the data, the process of coding leads to the development of theories through a process of abstraction. ${ }^{17}$ Glaser and Strauss, the original proponents of this approach, identify four main overlapping stages in the process of data collection and analysis when developing a grounded theory. ${ }^{17}$ These are: the constant comparative method, theoretical sampling, a search for negative cases, and data saturation. The constant comparative method is where each category is searched within the entire data and all instances are compared until no new categories can be identified. ${ }^{18}$ When categories emerge as theoretically relevant to the phenomenon in question, the data can be changed from a descriptive account into something that has a more explanatory power; this is known as theoretical sampling. For example, the category of 'having the authority to tell' emerged as a major theme 'authority within a family' in the study by Forrest et al., on family communication about genetic risk. ${ }^{12}$ Since ongoing coding and analysis is essential in a grounded theory approach, the theoretical concerns that emerge from the data should also determine what or who will be investigated next. A further stage is to search for negative cases within the data, that is, for alternative explanations to that which is being developed. ${ }^{17}$ Data saturation is reached when no additional data can be found with which to develop the properties of a particular category or concept and data collection and analysis is usually stopped at this stage. ${ }^{17}$ In practice, many researchers have adopted a modified version of grounded analysis drawing upon these approaches but without building a grounded theory per se. ${ }^{19}$

\section{Discourse analysis/conversation analysis}

Discourse analysis and conversation analysis are not the same but have a common theoretical basis and are broadly similar methods of analysis. ${ }^{20,21}$ The emphasis in these approaches is on interaction, and initially seeks to ask 'how' something is being achieved rather than 'why'.22,23 Conversation analysts describe and analyse language use and build from a base of language and communication to understand the nature of roles and relationships. ${ }^{4}$ As the emphasis is on the conversation and discourse, transcripts of interviews are usually very detailed to show all elements of interaction. Transcriptional conventions have been developed to show, for example, increased volume, prolonged sounds, breaths and simultaneous speech. ${ }^{20,21}$ The basic analytical unit in conversational analysis is a turn, whether a single utterance or full sentence. The transcripts are analysed for patterns of interaction such as turn-taking or other analytical units and the data extract is referenced to indicate interaction code, position on tape and date. ${ }^{24}$ Hence Jones' use of conversation analysis revealed that nurses' questions were orientated in such a way as to restrict the patient's ability to communicate additional information. ${ }^{24}$ The nurses managed the turn-taking and introduction of new topics and the patients had little opportunity to organise the talk, or turn-taking.

\section{Analysis of images}

This paper has focused on the analysis of textual data, but visual data, including photographs and videos, may also be used in qualitative research. Marvasti outlines the four main uses of visual data: (1) 'researcher-generated' visual data as the primary source of data and method of representing the findings; (2) visual data as a complement to the written text or as a way of telling ethnographic tales; (3) visual data as a way of eliciting interviews and other data; and (4) 'found' photographic or filmic materials for secondary data analysis. ${ }^{25}$

Coding up or coding down is equally as applicable to the analysis of visual data as textual data. Predefined categories can be used to identify patterns in photographs or videos that may not be noticeable on casual inspection. ${ }^{25}$ Both the image and its context require analysis, including answers to the question of why this image was taken of this subject at this time..$^{25}$ Thematic analysis can be used to analyse aspects of behaviour in videos as well as verbal communication. ${ }^{26}$ Conversation /narrative analysis may also be adapted.27 Olsson et al., for instance, combined content analysis and a discourse analysis approach with analysing videos of anteand postnatal midwifery consultations. ${ }^{28}$

\section{General issues in qualitative data analysis}

There are a number of further general issues to consider when undertaking qualitative analysis. First, an initial quantitative representation of (some of) the data can be acceptable and illuminating. ${ }^{6}$ Thus one could say that nine out of ten interviewees were very positive about in vitro fertilisation as they stated: "(list your example quotes here)". 
Second, people have questioned to what extent qualitative research can uncover the 'truth'. This is referred to as epistemology (or theory of knowledge), which may be considered in terms of the relationship between the observer and the observed. How one views and analyses this relationship differs depending on whether one views social phenomena as 'things in their own right' or 'representations of things'. ${ }^{29}$

As qualitative research addresses questions such as: 'Why do people do the things they do?' and 'What is the meaning of an event or phenomenon for someone?' it could be argued that we can (or must) take such accounts at face value. However, we may tell different stories to different people at different times when describing the same event. Hence Jamieson has drawn our attention to the public and private stories which people may tell. ${ }^{30}$ Although public accounts are not false per se, they tend to draw on ideals and stereotypes rather than the detailed complexity of everyday life. Accordingly they are: "a repertoire of themes, stereotypes and judgements concerning mothering, fathering, parenting, befriending, sex, dating, marrying, loving and the like for recycling or adaptation when making sense of, justifying or glamorizing personal life". 30

Private stories, in contrast, are the complex, contradictory, discordant accounts of people's everyday lives that may be deeply intertwined with these more public stories. Hence the accounts which people give are more likely to represent one particular view rather than everything that could be said or observed.$^{30}$ Nevertheless, a critical theoretical lens should help to illuminate the relationship between these public and private discourses, and the gaps between what people say and what they in fact do. [NB. The choice of which theoretical lens to use is also a fundamental part of the analytic process. According to some, theory "can never be disproved but only found to be more or less useful". ${ }^{13}$ It is suggested that theory be likened to a camera lens because a different focus will illuminate the world in different ways and in turn lead to different conclusions.]

Third, regardless of how one chooses to analyse and present the data there should be sufficient explanation of how you 'got there'. ${ }^{6}$ Two important issues are the provision of an audit trail and a reflexive account.

\section{Audit trail}

Careful documentation should be kept for all aspects of the research process including approaching and gaining consent from participants, recording participants who decline to participate, sampling decisions, data collection, any problems arising and data analysis. This allows an explicit account of how the research was conducted and underlines the dependability of the study's findings. "Maintaining and reporting an audit trail of methodological and analytic decisions allows others to assess the significance of the research." 31

\section{Reflexivity}

Reflexivity occurs when researchers critically reflect upon the process of data collection and analysis and how it has been influenced by the social, historical, political and personal context. ${ }^{2}$ For example, as qualitative research around family planning and reproductive health can often involve discussing sensitive and personal issues the researcher must reflect on the extent to which they may have inhibited or facilitated the respondent to discuss such issues openly. Thus, according to Holland and Ramazanoglu, "power relations in the research process can be recognized and made overt, but differences such as age, class, gender, ethnicity and religion impinge on the possibilities of interaction and interpretation and, so, on how the social world is known".32

\section{Final remarks}

This paper has outlined some of the different ways one can analyse visual and non-visual qualitative data and discussed some of the issues that can arise in data management and coding. The paper should go some way to helping readers think about how to 'do' qualitative analysis as well as choose the most appropriate approach for their study. Whatever method of analysis is chosen, there is a need for transparency to enable readers to assess the quality of the data collection, analysis and reporting. The issues around how to write up and disseminate the findings of a qualitative study will form the basis of the final paper in this miniseries on qualitative research.

Statements on funding and competing interests

Funding. Karen Forrest Keenan has been employed on two Wellcome Trust grants.

Competing interests. None identified.

References

1 van Teijlingen E, Forrest Keenan K. The range of qualitative research methods in family planning and reproductive health care. $J$ Fam Plann Reprod Health Care 2004; 30: 171-173.

2 Forrest Keenan K, van Teijlingen E. The quality of qualitative research in family planning and reproductive health care. $J$ Fam Plann Reprod Health Care 2004: 30: 257-259.

3 Burgess R (ed.). Field Research: A Sourcebook and Field Manual. London, UK: George Allen \& Unwin, 1984.

4 Miles MB, Huberman AM. Qualitative Data Analysis (2nd edn). Thousand Oaks, CA: Sage, 1994.

5 Huberman AM, Miles MB. Data management and analysis methods In: Denzin NK, Lincoln YS (eds), Collecting and Interpreting Oualitative Materials. Thousand Oaks, CA: Sage, 1998.

6 Mason J. Qualitative Researching (2nd edn). London, UK: Sage, 2002.

7 Barry CA. Choosing qualitative data analysis software: Atlas/ti and Nudist compared. Sociological Research Online 1998; 3(3). http://www.socresonline.org.uk/socresonline/3/3/4.html.

8 Wester F, Peters V. Qualitative analysis: phases, techniques and computer use. In: Pole CJ, Burgess RG (eds), Cross-Cultural Case Study. Amsterdam, The Netherlands: Elsevier Science, 2000.

9 O'Reilly K. Ethnographic Methods. London. UK: Routledge, 2004.

10 Flick U. An Introduction to Qualitative Research. London. UK: Sage, 2002.

11 Kingori P, Wellings K, French R, Kane R, Gerressu M, Stephenson J. Sex and relationship education and the media: an analysis of national and regional newspaper coverage in England. Sex Educ 2004; 4 111-124.

12 Forrest K, Simpson SA, Wilson BJ, van Teijlingen ER, McKee L, Haites $\mathrm{N}$, et al. To tell or not to tell: barriers and facilitators in family communication about genetic risk. Clin Genet 2003; 64: 317-326.

13 Silverman D. Interpreting Qualitative Data: Methods for Analysing Talk, Text and Interaction. London, UK: Sage, 2001.

14 Hammersley M, Atkinson P. Ethnography: Principles in Practice. London, UK: Tavistock, 1983

15 Fielding N. Analysing qualitative data by computer. Social Research Update, Issue 1. Guildford, UK: University of Surrey, 1993 http://www.soc.surrey.ac.uk/sru/SRU1.html.

16 Strauss AL, Corbin JM. Basics of Qualitative Research: Grounded Theory Procedures and Techniques. London, UK: Sage, 1990.

17 Glaser BG, Strauss AL. The Discovery of Grounded Theory: Strategies for Qualitative Research. Chicago. IL: Aldine, 1967.

18 Pope C, Mays N. Qualitative research: reaching the parts other methods cannot reach: an introduction to qualitative methods in health and health services research. BMJ 1995; 311: 42-45.

19 Long NH, Johansson E, Diwan VK, Winkvist A. Fear and social isolation as consequences of tuberculosis in Vietnam: a gender analysis. Health Policy 2001; 58: 69-81.

20 Lee RM, Fielding NG. Tools for qualitative data analysis. In: Hardy M, Bryman A (eds), Handbook of Data Analysis. London, UK: Sage, 2004; 529-546.

21 Potter J. Discourse analysis. In: Hardy M, Bryman A (eds), Handbook of Data Analysis. London, UK: Sage, 2004; 607-624.

22 Clayman SE, Gill VT. Conversation analysis. In: Hardy M, Bryman A (eds), Handbook of Data Analysis. London, UK: Sage, 2004; $589-606$.

23 McKinlay E, Plumridge L, McBain L, McLeod D, Pullon S, Brown S. "What sort of health promotion are you talking about?" A discourse analysis of the talk of general practitioners. Soc Sci Med 2004; (in press). 
24 Jones A. Nurses talking to patients: exploring conversation analysis as a means of researching nurse-patient communication. Int J Nur Stud 2003; 40: 609-618.

25 Marvasti AB. Qualitative Research in Sociology. London, UK: Sage, 2004

26 Rich M, Lamola S, Gordon J, Chalfen R. Video intervention/prevention assessment: a patient-centred methodology for understanding the adolescent illness experience. $J$ Adolesc Health 2000; 27: 155-165.

27 Heath C. Analyzing face-to-face interaction: video, the visual and material, In: Silverman D (ed.), Qualitative Resarch: Theory, Method and Practice. London, UK: Sage, 2004

28 Olsson P, Jansson L, Norberg A. A qualitative study of childbirth as spoken about in midwives' ante- and postnatal consultations Midwifery 2000; 16: 123-134

29 Corbetta P. Social Research: Theory, Methods and Techniques. London, UK: Sage, 2003.

30 Jamieson L. Intimacy: Personal Relationships in Modern Societies Cambridge, UK: Polity Press, 1998

31 Rice PL, Ezzy D. Qualitative Research Methods: A Health Focus South Melbourne, Australia: Oxford University Press, 1999.

32 Holland J, Ramazanoglu C. Coming to conclusions: power and interpretation in researching young women's sexuality. In: Maynard M, Purvis J (eds), Researching Women's Lives from a Feminist Perspective. London, UK: Taylor \& Francis, 1994.

\section{Book Review}

Abortion in the USA and the UK. Colin Francome. Aldershot, UK: Ashgate Publishing Ltd, 2004. ISBN: 075463015 3. Pages: 154 . Price: $£ 35.00$ (hardback)

Colin Francome has devoted much of his academic life to researching the abortion issue and this book provides an insightful account of his findings. Comparing the USA and UK throughout, it begins in the present, outlining the realities of the provision of, and demand for, abortion. It moves back in time, summarising the processes through which abotion was legalised over three decades ago, and forward again with an account of the political debate to the present.

The overriding similarity between these two societies is evident in data presented about the demand for abortion. Some specifics are highlighted - for example, why the abortion rate is higher in the USA - but overall it is clear that is higher in the USA - but overall it is clear that for women in both societies abottion was, is. drawn to differences, most clearly in the legal and political aspects. Women in the USA have legal provision for 'the right to choose' which they lack in the UK (very obviously in Northern Ireland where the Abortion Act does not apply). But in the UK the political movement to oppose lega abortion is relatively weak, meaning contest over abortion is muted by comparison.

An unprecedented victory for the American anti-abortion movement discussed by Francome is the recent passing of a law by the US Congress which, for the first time in American history, bans a particular medical procedure, termed by its opponents 'partial birth abortion'. Other event under the Bush administration indicate similarly the extent to which abortion remains politicised by its opponents' activities.

But it would be wrong to imagine that opposition to abortion is not important in Britain. Recent events make it clear that despite the relative weakness of the religiously inspired campaign for the 'right to life of the unborn', abortion is contentious. Over the last year, high-profile public debate has crystallised around abortion for fetal abnormality, in particular cleft palate, and 'late' abortion, carried out for any reason. Francome includes statistics in his bok that show that these abotics statistically marginal, yet they have moved to the centre of the British abortion controversy.

The dominance of argument hostile to provision of abortion in these cases is striking. What is also notable is that its proponents come in many forms. Feminists including Naomi Wolf and Yasmin Alibhai-Brown have voiced their 'disquiet' about abortion after 12 weeks, as have clinicians who work in obstetrics. Journalists clinicians who work in abstetics. Jounalists fixated images and with the very attractive current champion of the 'rights' of the abnormal fetus, the Reverend Joanna Jepson, have joined in. Some in the disability rights lobby play an important role in portraying abortion for abnormality as 'eugenic'. Politicians including David Steel are arguing for a reduced upper time limit.

Francome reminds us that the woman is, always, the person who should have the moral authority to decide whether to end a pregnancy. Those who agree with this standpoint need to be aware the abortion debate has moved on, and presents us with new challenges.

Reviewed by Ellie Lee, BSc, PhD

Lecturer in Social Policy, School of Social Policy, Sociology and Social Research, University of Kent, Canterbury, UK

\section{Journal of Family Planning and Reproductive Health Care}

\section{PEER REVIEWERS 2004}

Dr Mandy Abushama, Dr S Ariyanayagam, Dr Lesley Bacon, Dr Urszula Bankowska, Dr Derrick Bennett, Dr Sharon Bodard, Mr Peter Bowen-Simpkins, Dr Audrey Brown, Dr Jonathan Burton, Dr Jeanette Cayley, Dr Hilary Cooling, Mr Michael L Cox, Miss Angela Crook, Dr Elizabeth Devonald, Professor Lindsay Edouard, Dr Karen Fairhurst, Professor Richard Farmer, Dr Caroline Free, Dr Ruth Garside, Dr Deborah Gill, Professor Anna Glasier, Assistant Professor James Gribble, Dr Malcolm Griffiths, Dr Sunanda Gupta, Professor Philip Hannaford, Ms Linda Hayes, Dr Jennifer Hopwood, Dr Andrew Horne, Mr Roy Husemeyer, Dr Margaret Kingston, Dr Gunta Lazdane, Dr Medard Lech, Dr Amanda Lee, Dr Anne MacGregor, Mr Graeme Maclennan, Dr Diana Mansour, Dr Louise Massey, Dr John McEwan, Miss Angela Mills, Dr Helen Mitchell, Dr Jill Mollison, Dr Judy Murty, Dr Kate Nash, Dr Lesley Navaratne, Professor John Newton, Dr Alison Parkes, Dr Anthony Parsons, Miss Katherine Paterson, Dr Steve Patterson, Dr Clare Payne, Mrs Hilary Piercy, Mr Gordon Prescott, Dr Craig Ramsay, Dr Sarah Randall, Dr Fran Reader, Professor Lesley Regan, Dr Christine Robinson, Dr Gillian Robinson, Dr Clémentine Rossier, Dr Sam Rowlands, Mr Bhanu Ruparelia, Mr Neil Scott, Dr Stephen Searle, Professor Samual Shapiro, Mrs Jill Shawe, Dr Lindsay Smith, Dr Imogen Stephens, Dr Lesley Sutcliffe, Assistant Professor Stephanie Teal, Dr Ros Tolcher, Dr Gillian Vanhegan, Professor Gillian Wakley, Dr Martyn Walling, Dr Pam Warner, Dr Anne Webb, Dr Edith Weisburg, Miss Ley-Mee Yu, Professor Sue Ziebland

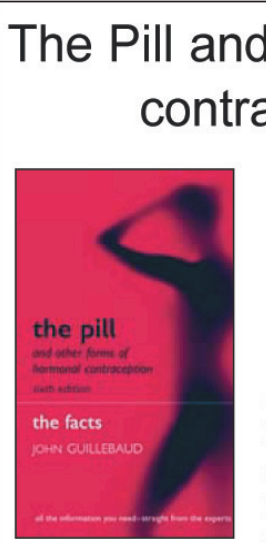

John Guillebaud, Emeritus Professor of Family Planning and Reproductive Health, University College London; Honorary Consultant in Family Planning and Reproductive Health, Oxford Primary Care Trust; formerly Medical Director, the Margaret Pyke Centre, London, UK

During the 40 years since the Pill was first marketed, more money has been spent researching its safety than was spent on its development through the 1950s. Although it has repeatedly been established it as one of the least harmful medicines ever formulated, there are some risks, and a number of 'Pill scares' have been reported in the media. Following each of these many women give up the Pill, and do not always find a satisfactory alternative. Professor Guillebaud gives a balanced explanation of the risks, benefits and sideeffects and his book is based on the latest and best research evidence. The sixth edition of this popular handbook is still the only book to give comprehensive information - with no fudging on the unwanted side effects - about the Pill and related hormonal methods of contraception. The author, an experienced prescriber and trusted medical author, writes in a clear and accessible way, He believes strongly in women's autonomy: 'the user is always the chooser'.

December 2004 | 0-19-856613-1 | Paperback | 307 pages | £12.99 TO ORDER

TEL: +44 (0)1536 454534 TEL: 1-800-451-7556

FAx: +44 (0)1536 454518 FAx: 1-919-677-1303

OXFORD 